\title{
Prescription of potentially inappropriate medications in elderly outpatients: a survey using 2015 Japanese Guidelines
}

\author{
Keiko Fujie ${ }^{1}$ [ $\cdot$ Risa Kamei $^{2} \cdot$ Risa Araki $^{1} \cdot$ Koichi Hashimoto $^{1}$
}

Received: 27 August 2019 / Accepted: 8 January 2020 / Published online: 21 January 2020

(c) The Author(s) 2020

\begin{abstract}
Background In recent years, rapid increase of elderly population has become a major social problem in developed countries. They tend to receive an increasing number of prescibed drugs due to multiple illnesses, which might include inappropriate medications, in turn leading to health hazards and rising healthcare cost. Objective To evaluate the current status of potentially inappropriate medications prescribed for elderly outpatients and filled by dispensing pharmacies using the recent Japanese Guidelines, and to determine factors that are related to prescribing potentially inappropriate medications. Setting A crosssectional study of older patients ( $\geq 75$ years) who visited dispensing pharmacies in the Ibaraki Prefecture, Japan. Method We identified patients prescribed potentially inappropriate medications using the "List of Medications that Require Particularly Careful Administration" in the Guidelines (Guideline List). We explored patient's factors related to polypharmacy ( $\geq 5$ medications) and prescription of inappropriate medications through multivariate analysis, and a cutoff value for predicting potentially inappropriate medications through receiver operating characteristic curve analysis. Main outcome measure Prevalence of polypharmacy and potentially inappropriate medications, and patient's factors associated with them. Results Of 8080 patients (39,252 medications) who visited pharmacies during the study period, $43.1 \%$ (3481) were prescribed $\geq 5$ medications. In total, 2157 patients (26.7\%) were prescribed at least one potentially inappropriate medication. The most prescribed inappropriate medication class was (benzodiazepine) sedatives and hypnotics. Potentially inappropriate medications were 7.11 times (95\% CI 6.29-8.03) and 1.51 times (1.34-1.71) more likely to be prescribed for patients with $\geq 5$ medications and those prescribed by multiple physicians, respectively. A cutoff value for potentially inappropriate medications was found to be five for the total number of medications and four for the number of chronic medications with a systemic effect. Conclusion Prescription of potentially inappropriate medications was increased among patients with $\geq 5$ medications and those chronically prescribed $\geq 4$ medications with a systemic effect. The Guideline List should be actively used to screen such patients, and to carefully examine prescriptions. Particular care should be exercised when patients are visiting multiple physicians.
\end{abstract}

Keywords Dispensing pharmacy $\cdot$ Guideline $\cdot$ Japan $\cdot$ Outpatient $\cdot$ Polypharmacy $\cdot$ Potentially inappropriate medication

\section{Impacts on practice}

Keiko Fujie

k-fujie@md.tsukuba.ac.jp

1 Department of Clinical and Translational Research Methodology, Faculty of Medicine, University of Tsukuba, 1-1-1 Tennodai, Tsukuba, Ibaraki 305-8575, Japan

2 Graduate School of Comprehensive Human Sciences, University of Tsukuba, 1-1-1 Tennodai, Tsukuba, Ibaraki 305-8575, Japan
- To prevent polypharmacy and PIMs, it is necessary for elderly outpatients to avoid being prescribed medication by multiple physicians as much as possible.

- Pharmacists at dispensing pharmacies and physicians must be encouraged to proactively check if there are PIMs in the prescriptions when elderly outpatients are prescribed $\geq 5$ medications or $\geq 4$ chronic-phase systemic drugs.

- Physicians are expected to regularly review the prescriptions for the elderly, and to take particular care to prescribe bennzodiazepine sedatives and hypnotics. 


\section{Introduction}

In recent years, the rapidly increasing number of elderly people in the Japanese population has become a major social problem. The World Health Organization (WHO) defines societies with an aging rate (the percentage of the total population that is aged $\geq 65$ years ) $>21 \%$ as "superaged societies" [1]. With an aging rate of $28.1 \%$ in 2018 [2], Japan is categorized as a super-aged society. The aging of society is not limited to Japan and other developed countries, which is also the case even in developing countries in Asia [1]. As people age, they tend to take an increasing number of medical treatments including drug prescription, which may lead to health hazards. The elderly people are susceptible to adverse drug events (AEs) [3] for two main reasons; the first being "polypharmacy", which is generally considered to be a situation in which a patient is taking five or more medications, is more common due to the increasing number of co-morbidities [4]. As reported [5-7], the cutoff of five medications is based on the increased risk of falling, frailty, and death among the elderly. Other studies have reported that increase in the number of prescribed drugs elevates the risk of being prescribed potentially inappropriate medications (PIMs) and of developing AEs [8-11]. The second reason is because people's ability to metabolize drugs is decreased as they age due to physiological changes including reduced liver and renal functions [12]. Drug sensitivity is also increased in elderly people; even small doses of a drug can lead to AEs. For the abovementioned reasons, reducing the number of unnecessary and inappropriate prescriptions for the elderly is a major issue in clinical settings. Studies have suggested that polypharmacy leads to AEs due to drug interactions, dispensing errors, and errors associated with medicine use, but is also associated with underuse [13, 14]. Thus, this is an issue that is related to all aspects of the appropriateness of prescriptions.

Given that these background circumstances are common in advanced nations of the world, the safety of the pharmacotherapy provided to the elderly has come to be recognized as an important global problem. This has led to submission of the Beers Criteria [15, 16] and the screening tool of older people's prescriptions (STOPP)/screening tool to alert to right treatment (START) Criteria $[17,18]$. In Japan, the Guidelines for the Safety of Pharmacotherapy in the Elderly was released in 2015 (GL2015) [12]. These guidelines were directed to the elderly aged $\geq 75$ years, who are "old-old" in the Japanese medical insurance system. The GL2015 comprises a "List of Medications that Require Particularly Careful Administration" which indicates PIMs, and a "List of Medications that should be Considered for Administration" which is designed to eliminate underuse. Despite the necessity of reducing PIMs, there is still little data on polypharmacy and PIMs among elderly patients in Japan, resulting in insufficient appreciation of this problem among healthcare professionals that has direct contact with patients' prescriptions.

\section{Aim of the study}

The aim of this study was to evaluate the current status of polypharmacy and PIMs among elderly outpatients whose prescriptions were filled by dispensing pharmacies in Japan, and to find patient's factors associated with prescription of PIMs.

\section{Ethics approval}

The study protocol was approved by the Medical Institutional Review Boards of the University of Tsukuba. This study utilized anonymized data from dispensing pharmacies. Information regarding this study was disclosed on the homepage of our research laboratory.

\section{Method}

\section{Subjects and setting}

We conducted a retrospective cross-sectional study. The study subjects were elderly outpatients aged $\geq 75$ years whose prescriptions were filled at dispensing pharmacies in urban and suburban areas of Ibaraki Prefecture, Japan. The number of targeted pharmacies throughout the prefecture was 12 , nine of which were located in the vicinity of regional core hospitals. Anonymized data from the pharmacies included the following: pharmacy, prescription number, patient identification number, age, sex, name and number of beds of prescribing medical facility, prescribing medical department, brand name, content and price of each medication, and number of days the medication was prescribed for. The following patient background data were unavailable: history of the current illness, complications, and laboratory test data.

In Japan, mostly, patients with chronic diseases are seen at the outpatient department once a month. To prevent repeated use of the same patient's data and to account for the possibility that some patients may visit the outpatient department at intervals longer than 30 days, we extended the study period by 10 days (total of 40 days) from February 1 to March 12, 2015 (the period with the fewest number of single and consecutive holidays in the year). Age of the subject was defined as the age on the first prescription during 
the study period, except that patients who turned 75 years during the period were regarded as 75 years. All subjects aged $\geq 85$ years were listed as " 85 " in the data.

\section{Definition of prescription and polypharmacy}

We considered that prescriptions from the same medical department at the same medical facility were given by the same physician. In patients with $\geq 2$ prescriptions during the study period, only the data of the first prescription by the same physician were utilized. Thus, the number of prescriptions for a single patient matched the number of physicians who examined the patient. Prescriptions written by different physicians were regarded as those for different medications, and therefore each medication was included in the total number of medications for the patient. "Polypharmacy" was defined as cases in which the total number of medications was $\geq 5$ [3-5]. We also counted "chronicphase systemic drugs", which included oral, self-injectable, and systemic external drugs (designed to be absorbed into the bloodstream), and excluded "acute-phase prescriptions ( $\leq 7$ days)".

\section{Screening for PIMs}

In this study, "the List of Medications that Require Particularly Careful Administration" in GL2015 (STOPP-J) [12], which includes medications intended for long-term administration, was used for PIMs screening. The drugs in the list are organized into 20 categories and 29 classes.
Specifically, only the drug classes, which could be clearly determined from the data to correspond to medications that they "should not be used" or that their "use should be kept to the minimum possible", were targeted for screening. Drug classes with recommended administration period or doses were excluded from screening because such data were not available. Thus, 11 categories and 13 classes of drugs were adopted in this study (Table 1). We investigated the generic names of the compounds in each drug class and subsequently searched for their brand names using the Kyoto Encyclopedia of Genes and Genomes (KEGG) DRUG Database (www.genome.jp/kegg/).

Using the brand names identified above, we screened for PIMs among the drugs included in the prescriptions. For each drug category, we indicated the total numbers of relevant drugs, prescriptions including PIMs, and patients prescribed PIMs. In situations with multiple categories of PIMs in the same prescription for a patient, we considered that as an overlap, and also counted the actual number of prescriptions and patients after removing the overlapping numbers.

\section{Statistical analysis}

We calculated the median, interquartile range (IQR), and maximum values of the number of medications for each patient. In order to identify patient's factors that are related to polypharmacy, the Chi square test for categorical variables and the Mann-Whitney U test for continuous variables were performed, with statistical significance set at $P<0.05$ on both sides. We also performed multivariate
Table 1 Drug classes from the "List of Medications that Require Particularly Careful Administration (STOPP-J)" that were screened in this study

\begin{tabular}{|c|c|c|}
\hline Category & Drug class & Recommended use \\
\hline Sleeping drugs & $\begin{array}{l}\text { Benzodiazepine-based sleeping drugs } \\
\text { and anti-anxiety drugs }\end{array}$ & $\begin{array}{l}\text { Do not use long-lasting } \\
\text { effect type and tria- } \\
\text { zolam } \\
\text { Use the other benzodi- } \\
\text { azepines as little as } \\
\text { possible }\end{array}$ \\
\hline Anti-depressants & Tricyclic anti-depressants & Use as little as possible \\
\hline Sulpiride & Sulpiride & Use as little as possible \\
\hline Anti-Parkinson drugs & anti-Parkinson drugs & Use as little as possible \\
\hline Alpha blockers & $\begin{array}{l}\text { Receptor subtype non-selective } \alpha_{1} \\
\text { receptor blockers }\end{array}$ & Use as little as possible \\
\hline First generation $\mathrm{H}_{1}$ blockers & First generation $\mathrm{H}_{1}$ blockers & Use as little as possible \\
\hline $\mathrm{H}_{2}$ blockers & $\mathrm{H}_{2}$ blockers & Use as little as possible \\
\hline Antiemetics & antiemetics & Use as little as possible \\
\hline \multirow[t]{3}{*}{ Anti-diabetes drugs } & Sulfonylurea & Do not use when possible \\
\hline & Biguanide & Do not use when possible \\
\hline & SGLT2 inhibitors & Use as little as possible \\
\hline Insulin & Sliding scale insulin & Use as little as possible \\
\hline Overactive bladder drugs & Oxybutynin & Use as little as possible \\
\hline
\end{tabular}

SGLT2 sodium-glucose co-transporter 2 
logistic regression analysis, calculated the adjusted odds ratio (aOR) and the 95\% confidence interval (CI) for each factor, and investigated their relationship with polypharmacy. The results of PIM screening were included in the descriptive analysis and used to determine the factors related to PIMs as described for polypharmacy.

We performed receiver operating characteristic curve (ROC) analysis in order to determine whether the number of prescribed drugs is a useful indicator in predicting the presence of PIMs, and calculated the Youden Index [19] to search for the cutoff values for PIMs.

Data processing and analysis was performed using the Microsoft Excel 2016 and SPSS Statistics Version 24, respectively.

\section{Results}

There were 8080 patients aged $\geq 75$ ( $45.4 \%$ male) years who had their prescriptions filled at the target pharmacies over the 40-day study period. The patient background characteristics are shown in Table 2. The percentage of patients aged $\geq 85$ years was $25.6 \%$. The number of patients who were examined by $\geq 2$ physicians was 1829 (22.6\%). The maximum number of physicians who prescribed for a patient was six. The most common departments where patients received prescriptions were neurosurgery $(17.1 \%)$ and general internal medicine (16.3\%). Nearly half of the prescriptions were issued from relatively small medical facilities with $\leq 99$ beds.
Table 2 Patient background characteristics and total number of medications

\begin{tabular}{|c|c|}
\hline & $\begin{array}{l}\text { Total no. of patients } \\
n=8080\end{array}$ \\
\hline \multicolumn{2}{|l|}{ Sex, n (\%) } \\
\hline Male & $3668(45.4)$ \\
\hline Female & $4412(54.6)$ \\
\hline \multicolumn{2}{|l|}{ Age, $\mathrm{n}(\%)$, years } \\
\hline $75-84$ & $6009(74.4)$ \\
\hline 85 and above & $2071(25.6)$ \\
\hline \multicolumn{2}{|c|}{ No. of prescribing physicians per patient, n (\%) } \\
\hline 1 & $6251(77.4)$ \\
\hline 2 & $1365(16.9)$ \\
\hline 3 & $361(4.5)$ \\
\hline 4 & $77(1.0)$ \\
\hline 5 & $20(0.2)$ \\
\hline 6 & $6(0.1)$ \\
\hline \multicolumn{2}{|l|}{ Departments, $\mathrm{n}(\%)^{\mathrm{a}}$} \\
\hline Neurosurgery & $1795(17.1)$ \\
\hline General internal medicine & $1715(16.3)$ \\
\hline Orthopedic surgery & $1358(12.9)$ \\
\hline Ophthalmology & $1322(12.6)$ \\
\hline Cardiovascular medicine & $883(8.4)$ \\
\hline Others & $3435(32.7)$ \\
\hline \multicolumn{2}{|l|}{ Bed no. of medical facilities, $\mathrm{n}(\%)^{\mathrm{a}}$} \\
\hline 300 and more & $3518(33.5)$ \\
\hline 100-299 & $2075(19.7)$ \\
\hline 99 and less & $4915(46.8)$ \\
\hline \multicolumn{2}{|c|}{ No. of prescribed drugs per patient, median (IQR), [max] } \\
\hline Overall & $4(2-7)[28]$ \\
\hline Chronic-phase systemic drugs & $3(1-6)[25]$ \\
\hline
\end{tabular}

$I Q R$ interquartile range

${ }^{a} \mathrm{n}=10,508$ was the total number of prescriptions, including multiple prescriptions per patient 
The total 39,252 medications after exclusion of at least the second prescription by the same physician were included in our analyses. Among the overall total of medications, there were 32,313 oral drugs, 192 self-injectable drugs, 239 systemic external drugs, and 1949 acute-phase internal drugs, resulting in 30,795 (78.5\%) chronic-phase systemic drugs. The median (IQR) and maximum values for the numbers of medications for each patient are shown in Table 2 . The maximum numbers of overall medications and chronicphase systemic medications were 29 and 25 , respectively.

Overall, 43.1\% (3481/8080) patients had polypharmacy. At univariate analysis, those aged $\geq 85$ years, and those who were prescribed by $\geq 2$ physicians had significantly higher percentages of polypharmacy $(P<0.001)$. No statistically significant difference was found between the sexes (Table 3). Our multivariate logistic regression analysis on polypharmacy showed that being aged $\geq 85$ years had the aOR of 1.37 (95\% CI 1.23-1.53) against aged $<85$ years, while being prescribed by one additional physician had the aOR of 5.73 (95\% CI 5.11-6.42) (Table 3).

The results of PIMs screening using the STOPP-J are shown in Table 4. Among 39,252 medications included in the analyses, 2905 (7.4\%) were inappropriately prescribed. Our analysis also indicated that $21.6 \%(2273 / 10,508)$ prescriptions included $\geq 1$ PIMs, and that $26.7 \%$ (2157/8080) patients were given prescriptions with $\geq 1$ PIMs. As shown in Table 4, 1460 (50.3\%), 632 (21.8\%), and 316 (10.9\%) of the PIMs were sleeping drugs, H2-receptor antagonists, and

Table 3 Analysis of factors related to polypharmacy

\begin{tabular}{|c|c|c|c|c|c|}
\hline & \multicolumn{3}{|l|}{ Univariate analysis } & \multicolumn{2}{|l|}{ Multivariate analysis } \\
\hline & $\begin{array}{l}\text { Non-polypharmacy }(<5 \\
\text { medications }) \\
\mathrm{n}=4599\end{array}$ & $\begin{array}{l}\text { Polypharmacy }(\geq 5 \\
\text { medications) } \\
\mathrm{n}=3481\end{array}$ & $P^{\mathrm{a}}$ & Adjusted $\mathrm{OR}^{\mathrm{b}}(95 \% \mathrm{CI})$ & $P^{\mathrm{c}}$ \\
\hline Sex, female, n (\%) & $2484(54.0)$ & $1928(55.4)$ & 0.219 & $1.02(0.92-1.12)$ & 0.739 \\
\hline Age, $\geq 85, \mathrm{n}(\%)$ & $1065(23.2)$ & $1006(28.9)$ & $<0.001$ & $1.37(1.23-1.53)$ & $<0.001$ \\
\hline $\begin{array}{l}\text { No. of prescribing physicians } \\
\text { per patient, } \geq 2, \mathrm{n}(\%)\end{array}$ & $385(8.4)$ & $1444(41.5)$ & $<0.001$ & $5.73(5.11-6.42)^{\mathrm{d}}$ & $<0.001$ \\
\hline
\end{tabular}

Adjusted confounding variables in the multivariate logistic regression analysis; sex, age and the number of physicians per patient

$O R$ odds ratio, $C I$ confidence interval

${ }^{\text {a }} P$ value according to $C h i$ square test

${ }^{\mathrm{b}}$ Odds ratio adjusted for sex, age, number of prescribing physicians per patient

${ }^{\mathrm{c}} P$ value according to the logistic regression analysis

${ }^{\mathrm{d}}$ Number of prescribing physicians per patient was treated as a continuous variable at multivariate analysis

Table 4 Results of PIMs screening based on the STOPP-J

\begin{tabular}{llll}
\hline Category of PIMs & $\begin{array}{l}\text { Medications qualified as } \\
\text { PIMs, n (\%) }\end{array}$ & $\begin{array}{l}\text { Prescriptions including } \\
\text { PIMs, n (\%) }\end{array}$ & $\begin{array}{l}\text { Patients pre- } \\
\text { scribed PIMs, } \\
\mathrm{n}(\%)\end{array}$ \\
\hline Sleeping drugs & $1460(50.3)$ & $1276(48.5)$ & $1251(48.2)$ \\
Antidepressants & $27(0.9)$ & $27(1.0)$ & $27(0.3)$ \\
Sulpiride & $21(0.7)$ & $21(0.8)$ & $20(1.0)$ \\
Anti-Parkinson drugs & $6(0.2)$ & $6(0.2)$ & $6(0.2)$ \\
Alpha blockers & $221(7.6)$ & $217(8.3)$ & $216(8.3)$ \\
First-generation H1 blockers & $17(0.6)$ & $17(0.6)$ & $16(0.6)$ \\
H2 blockers & $632(21.8)$ & $632(24.0)$ & $628(24.2)$ \\
Antiemetics & $35(1.2)$ & $35(1.3)$ & $35(1.3)$ \\
Diabetes drugs & $316(10.9)$ & $261(9.9)$ & $260(10.0)$ \\
Insulin & $160(5.5)$ & $128(4.9)$ & $127(4.9)$ \\
Overactive bladder drugs & $10(0.3)$ & $10(0.4)$ & $10(0.4)$ \\
Total & 2905 & $2630^{\mathrm{a}}$ & $2596^{\mathrm{a}}$ \\
& & $(2273)^{\mathrm{b}}$ & $(2157)^{\mathrm{b}}$ \\
\hline
\end{tabular}

$P I M$ potentially inappropriate medication, STOPP-J list of medications that require particularly careful administration

${ }^{\text {a }}$ Sum of each category

${ }^{\mathrm{b}}$ Actual number after eliminating overlaps 
diabetes drugs, respectively. When divided into two groups as non-polypharmacy ( $<5$ medications) and polypharmacy ( $\geq 5$ medications), PIMs were mostly sleeping drugs (nonpolypharmacy: 51.9\%, polypharmacy: 49.9\%), H2-receptor antagonists $(23.0 \% ; 21.5 \%)$, and diabetes drugs $(6.9 \%$, $11.8 \%$ ), in that order. Of all the patients with PIM, $27.0 \%$ $(583 / 2,157)$ were prescribed with multiple PIMs, and the maximum number of PIMs per patient was six.

In the univariate analysis comparing patients with or without PIMs, a significant difference was found in sex and the number of physicians who prescribed for a patient. The numbers of overall and chronic-phase systemic medications were also significantly associated with PIMs (Table 5). In the multivariate analysis, polypharmacy (aOR: $7.11,95 \% \mathrm{CI}$
6.29-8.03) and multiple physicians prescribing for a patient (1.51, 1.34-1.71) showed significant relationship with prescription of PIMs. Age was not found to be significantly related to PIMs before and after adjustment (Table 5).

The ROC, area under the curve (AUC), AUC $P$ value, and 95\% CI for PIMs are shown in Fig. 1. The AUCs for both the overall number of medications and the number of chronicphase systemic drugs exceeded $0.8(P<0.001)$. Thus, we estimated that these numbers have predictive ability for PIMs. The results indicated that the Youden Index reached a maximum value at 4.5 and 3.5, respectively. The ideal cutoff value for PIMs was found to be five for the overall number of medications and four for the number of chronic-phase systemic drugs.

Table 5 Analysis of factors related to PIMs

\begin{tabular}{|c|c|c|c|c|c|}
\hline & \multicolumn{3}{|c|}{ Univariate analysis } & \multicolumn{2}{|l|}{ Multivariate analysis } \\
\hline & $\begin{array}{l}\mathrm{PIMs}=\mathrm{No} \\
\mathrm{n}=5923\end{array}$ & $\begin{array}{l}\text { PIMs }=\text { Yes } \\
\mathrm{n}=2157\end{array}$ & $P^{\mathrm{a}}$ & Adjusted $\mathrm{OR}^{\mathrm{b}}(95 \% \mathrm{CI})$ & $P^{\mathrm{c}}$ \\
\hline Sex, female, n (\%) & 3192 (53.9) & $1220(56.6)$ & 0.033 & $1.10(0.99-1.23)$ & 0.084 \\
\hline Age, $\geq 85, \mathrm{n}(\%)$ & $1485(25.1)$ & $586(27.2)$ & 0.056 & $0.96(0.85-1.08)$ & 0.486 \\
\hline $\begin{array}{l}\text { No. of prescribing physicians per patient, } \\
\geq 2, \mathrm{n}(\%)\end{array}$ & 989 (16.7) & $840(38.9)$ & $<0.001$ & $1.51(1.34-1.71)$ & $<0.001$ \\
\hline Polypharmacy & $1800(30.4)$ & $1681(77.9)$ & $<0.001$ & $7.11(6.29-8.03)$ & $<0.001$ \\
\hline \multicolumn{6}{|l|}{ No. of drugs, median (IQR) } \\
\hline Overall & $3(2-5)$ & $7(5-10)$ & $<0.001^{\mathrm{d}}$ & & \\
\hline Chronic-phase systemic drugs & $2(1-4)$ & $6(4-9)$ & $<0.001^{\mathrm{d}}$ & & \\
\hline
\end{tabular}

Adjusted confounding variables in the multivariate logistic regression analysis; sex, age, the number of physicians per patient and polypharmacy $P I M$ potentially inappropriate medication, $O R$ odds ratio, $C I$ confidence interval, $I Q R$ interquartile range

${ }^{\text {a }} P$ value according to Chi square test

${ }^{\mathrm{b}}$ Odds ratio adjusted for sex, age, number of prescribing physicians per patient, and polypharmacy

${ }^{\mathrm{c}} P$ value according to logistic regression analysis

${ }^{\mathrm{d}} P$ value according to Mann-Whitney $\mathrm{U}$ test

Fig. 1 ROC curves for no. of drugs and PIMs. a Overall no. of drugs. b No. of chronic-phase systemic drugs. AUC, area under the curve; CI, confidence interval; ROC, receiver operating characteristics curve; PIM, potentially inappropriate medication
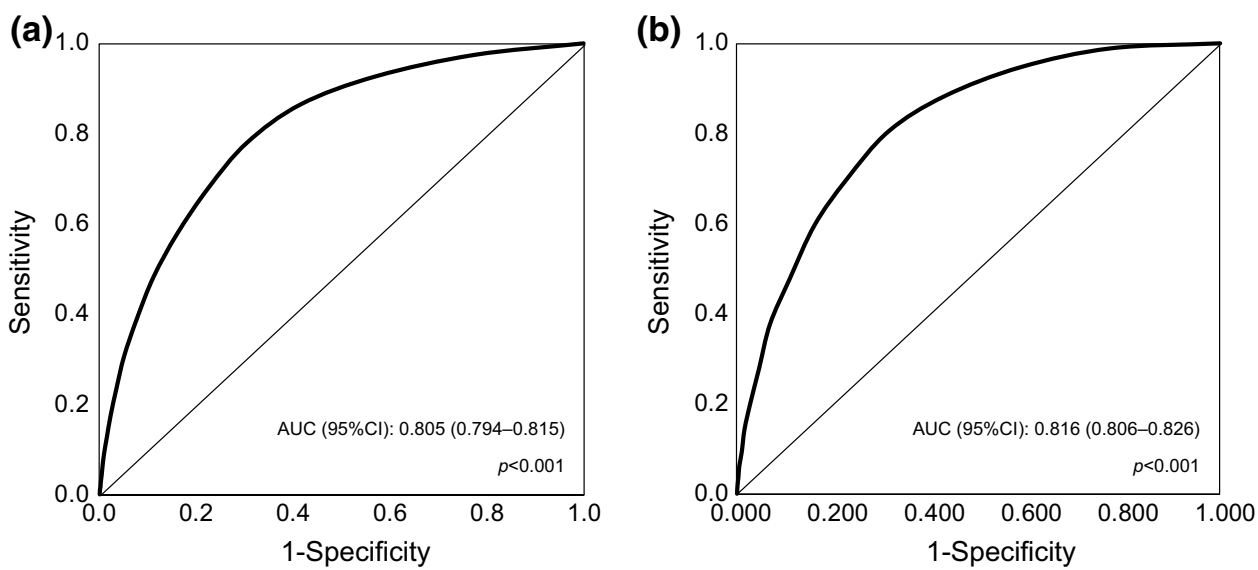


\section{Discussion}

In this study, we elucidated the current status of polypharmacy and PIMs based on the STOPP-J among the elderly outpatients in Japan. The results indicated that $43.1 \%$ of outpatients aged $\geq 75$ years experienced polypharmacy ( $\geq 5$ medications), and that $26.7 \%$ of them had at least one PIM.

Several previous studies [3,5-8] reported that, with increasing number of drugs prescribed, increased risk of drug interactions and drug duplications occurred, which subsequently increased the likelihood of AEs. Since many elderly people have multiple illnesses [5], prescriptions of long-term multiple drugs are inevitable. Furthermore, elderly people have reduced hepatic and renal functions which in turn make the experience of AEs more likely [20]. It is therefore advisable to reduce the number of medications prescribed for the elderly to the minimum required limit.

We found that $22.6 \%$ of the patients had been prescribed by $\geq 2$ physicians. The results of our multivariate analysis indicated that the risk of experiencing polypharmacy increased by 5.73 times (95\% CI 5.12-6.42) each time the patient was prescribed by one additional physician. In general, the number of illnesses a person suffers from increases with aging, and there is a tendency for people to visit more physicians and to be prescribed more medications. Prescriptions by multiple physicians would make it difficult for them to keep track of the medications being utilized by the patient. In addition, since it is difficult for the elderly to self-manage their drugs [21], they are more likely to experience AEs as the number of prescribing physicians increases [22]. To prevent $A E s$, physicians are required to prescribe new medications only after a thorough review of the medications being used by the elderly.

The largest percentage of drugs that qualified as PIMs were sleeping drugs (50.3\%). Since sleep disorders are more common as people age, there is a tendency for more sleeping drugs corresponding to PIMs to be prescribed to the elderly [23]. Benzodiazepines, the most commonly used sleeping medication, are known to increase the risk of falling among the elderly, therefore, it is recommended that a different sleeping drug be prescribed whenever possible [24, 25]. However, since benzodiazepines are habit-forming, it is often difficult for patients to stop their use immediately. It is effective to gradually reduce the dose while monitoring the patient's condition to ensure that withdrawal symptoms do not arise, until switching to another drug [24, 26].

Our multivariate analysis indicated that polypharmacy and being prescribed by multiple physicians were significantly related to PIMs. In addition, PIMs were significantly related to the number of prescribed drugs. As reported in previous studies [5-8], larger numbers of prescribed drugs increase the risk of PIMs, which is consistent with the present results. It was shown that $78.5 \%$ of medications prescribed to the elderly were long-term systemic medications; thus, it is important to pay more attention to such drugs. The results of our ROC analysis indicated that the cutoff values for PIMs for the overall number of drugs and for chronic-phase systemic drugs were five and four, respectively. This suggests that once these numbers are exceeded, there is a higher risk of PIMs. Therefore, in clinical settings, a careful examination and re-evaluation of the prescriptions issued to elderly patients aged $\geq 75$ years exceeding these cutoffs should be proactively conducted.

As the GL2015 is mainly concerned with safety, unlike treatment guidelines, prescribing drugs that qualify as PIMs may not necessarily be inappropriate. However, the drugs included in the STOPP-J have a high risk of causing AEs in the elderly; therefore, it is recommended that they should not be prescribed as far as possible, or that alternative medications be utilized. Recently another Japanese group also reported the current status of polypharmacy and PIMs in elderly people who visited dispensing pharmacies [27], however, they used the former edition of STOPP-J. In addition, they did not take multiple prescriptions for an elderly patient into consideration and not show a cutoff value of the number of drugs for predicting PIMs. We believe that the results of this study will contribute to increased propriety in prescriptions issued to elderly patients by indicating criteria to detect PIMs, and we expect that pharmacists at dispensing pharmacies play a role in the improvement of the prescriptions. Several studies have shown the efficacy of pharmacists' assessment and intervention on appropriate medications in hospitalized patients $[11,28]$. The similar trials are required to be conducted in elderly outpatients for the next step.

The present study had several limitations. First, since the study period was during winter, it is possible that the prescribed drugs may have some season-related differences. In order to investigate the possibility, we compared our data with data from the period between June 1 and July 10,2015 , resulting in no notable differences in the trends for polypharmacy and PIMs. Second, our prescription data were obtained from dispensing pharmacies in one prefecture, which might limit the generalization of our results to entire population of elderly people in Japan. However, we incorporated data from the whole geographical region and medical facilities into our analyses; therefore, we believe the results reflect real-world status of prescriptions in general elderly population. Finally, a patient who receives a prescription at an outpatient department might not always visit the same dispensing pharmacy, which suggests the possibility that we could not collect all prescriptions for a patient. In addition, we screened for PIMs for only drug classes which do not require other information than the drug name this time. Thus, when taking into consideration 
the administration period and dose of the drugs, it is predictable that a larger number of medications would have qualified as PIMs. Therefore, our results are likely an underestimation of the actual number of medications and PIMs.

\section{Conclusion}

The results of this study confirmed that polypharmacy is prevalent among elderly people, and that polypharmacy increased the risk of PIMs. It is recommended that proactive prescription screening using the STOPP-J be conducted in cases in which the overall number of drugs exceeds five, or the number of chronic-phase systemic drugs exceeds four. The results also indicated that being prescribed by multiple physicians was related to PIMs. Thus, it is necessary to proactively reduce the number of physicians who examine an elderly patient and to ascertain each patient's drug administration status at examinations.

Acknowledgements The authors would like to express their appreciation to Nihon Chouzai Co., Ltd, for providing the data utilized in this study.

Funding This study received support from the Grants-in-Aid for Scientific Research of the Japan Society for the Promotion of Science (No. 16K15229).

Conflicts of interest The authors declare no conflict of interest.

Open Access This article is licensed under a Creative Commons Attribution 4.0 International License, which permits use, sharing, adaptation, distribution and reproduction in any medium or format, as long as you give appropriate credit to the original author(s) and the source, provide a link to the Creative Commons licence, and indicate if changes were made. The images or other third party material in this article are included in the article's Creative Commons licence, unless indicated otherwise in a credit line to the material. If material is not included in the article's Creative Commons licence and your intended use is not permitted by statutory regulation or exceeds the permitted use, you will need to obtain permission directly from the copyright holder. To view a copy of this licence, visit http://creativecommons.org/licenses/by/4.0/.

\section{References}

1. Permanent Mission of Japan to the United Nations. Statement "Mainstreaming gender and aging in the SDGs". 12 July 2016. [Cited 15 Sep 2017]. Available from: https://www.un.emb-japan .go.jp/statements/okamura071316.html.

2. Statistics Bureau of Japan. Current population estimates as of October 1, 2018 [Cited 15 Nov 2019].http://www.stat.go.jp/english/data/ jinsui/2018np/index.html.

3. Toba K, Akishita M, Mizuno Y. Drug-induced diseases. J Jpn Geriatr Soc. 1999;36:181-5.

4. Suzuki Y, Akishita M, Arai H, Teramoto S, Morimoto S, Toba K. Multiple consultations and polypharmacy of patients attending geriatric outpatient units of university hospitals. Geriatr Gerontol Int. 2006;6:244-7.

5. Gnjidic D, Hilmer SN, Blyth FM, et al. Polypharmacy cut off and outcomes: five or more medicines were used to identify communitydwelling older men at risk of different adverse outcomes. J Clin Epidemiol. 2012;65:989-95.

6. Saum KU, Schöttker B, Meid AD, et al. Is polypharmacy associated with frailty in older people? Results from the ESTHER cohort study. J Am Geriatr Soc. 2017;65:e27-32.

7. Kojima T, Akishita M, Nakamura T, et al. Polypharmacy as a risk for fall occurrence in geriatric outpatients. Geriatr Gerontol Int. 2012;12:425-30.

8. Onder G, Petrovic M, Tangiisuran B, et al. Development and validation of a score to assess risk of adverse drug reactions among inhospital patients 65 years or older: the GerontoNet ADR risk score. Arch Intern Med. 2010;170:1142-8.

9. Varga S, Alcusky M, Keith SW, et al. Hospitalization rates during potentially inappropriate medication use in a large population-based cohort of older adults. Br J Clin Pharmacol. 2017;83:2572-80.

10. Dhall J, Larrat EP, Lapane KL. Use of potentially inappropriate drugs in nursing homes. Pharmacotherapy. 2002;22:88-96.

11. Kimura T, Ogura F, Yamamoto K, et al. Potentially inappropriate medications in elderly Japanese patients: effects of pharmacists' assessment and intervention based on screening tool of older persons' potentially inappropriate prescriptions criteria ver. 2. J Clin Pharm Ther. 2017;42:209-14.

12. Japan Geriatrics Society. Guidelines for medical treatment and its safety in the elderly. Tokyo: Medical View; 2015.

13. Wauters M, Elseviers M, Vaes B, et al. Too many, too few, or too unsafe? Impact of inappropriate prescribing on mortality, and hospitalization in a cohort of community-dwelling oldest old. Br J Clin Pharmacol. 2016;82:1382-92.

14. Jin $\mathrm{H}$, Tang $\mathrm{C}$, Wei Q, et al. Age-related differences in factors associated with the underuse of recommended medications in acute coronary syndrome patients at least one year after hospital discharge. BMC Cardiovasc Disord. 2014;14:127-35.

15. The American Geriatrics Society 2012 Beers Criteria Update Expert Panel. American Geriatrics Society updated Beers Criteria for potentially inappropriate medication use in older adults. J Am Geriatr Soc. 2012;60:616-31.

16. The American Geriatrics Society 2015 Beers Criteria Update Expert Panel. American Geriatrics Society. Updated beers criteria for potentially inappropriate medication use in older adults. J Am Geriatr Soc. 2015;2015(63):2227-46.

17. Gallagher P, Ryan C, Byrne S, Kennedy J, O’Mahony D. STOPP (Screening Tool of Older Person's Prescriptions) and START (Screening Tool to Alert doctors to Right Treatment). Consensus validation. Int J Clin Pharmacol Ther. 2008;46:72-83.

18. O'Mahony D, O'Sullivan D, Byrne S, O'Connor MN, Ryan C, Gallagher P. STOPP/START criteria for potentially inappropriate prescribing in older people: version 2. Age Ageing. 2015;44:213-8.

19. Youden WJ. Index for rating diagnostic tests. Cancer. 1950;3:32-5.

20. Schwartz JB. The current state of knowledge on age, sex, and their interactions on clinical pharmacology. Clin Pharmacol Ther. 2007;82:87-96.

21. Japan Geriatrics Society. Pharmacotherapy for the elderly: drug use guidance. In: Geriatric medicine textbook, 3rd ed. Tokyo: Medical View; 2008.

22. Green JL, Hawley JN, Rask KJ. Is the number of prescribing physicians an independent risk factor for adverse drug events in an elderly outpatient population? Am J Geriatr Pharmacother. 2007;5:31-9.

23. Neikrug AB, Ancoli-Israel S. Sleep disorders in the older adult: a mini-review. Gerontology. 2010;56:181-9. 
24. Markota M, Rummans TA, Bostwick JM, Lapid MI. Benzodiazepine use in older adults: dangers, management, and alternative therapies. Mayo Clin Proc. 2016;91:1632-9.

25. Díaz-Gutiérrez MJ, Martínez-Cengotitabengoa M, Sáez de Adana $\mathrm{E}$, et al. Relationship between the use of benzodiazepines and falls in older adults: a systematic review. Maturitas. 2017;101:17-22.

26. Lopez-Peig C, Mundet X, Casabella B, del Val JL, Lacasta D, Diogene E. Analysis of benzodiazepine withdrawal program managed by primary care nurses in Spain. BMC Res Notes. 2012;5:684.

27. Suzuki Y, Sakakibara M, Shiraishi N, Hirose T, Akishita M, Kuzuya M. Prescription of potentially inappropriate medications to older adults: a nationwide survey at dispensing pharmacies in Japan. Arch Gerontol Geriatr. 2018;77:8-12.

28. Hashimoto Y, Tensho M. Effect of pharmacist intervention on physician prescribing in patients with chronic schizophrenia: a descriptive pre/post study. BMC Health Serv Res. 2016;16:150.

Publisher's Note Springer Nature remains neutral with regard to jurisdictional claims in published maps and institutional affiliations. 